\title{
Extended metal-organic solids based on benzenepolycarboxylic and aminobenzoic acids
}

\author{
R MURUGAVEL*, G ANANTHARAMAN, D KRISHNAMURTHY, \\ M SATHIYENDIRAN and M G WALAWALKAR \\ Department of Chemistry, Indian Institute of Technology, Powai, \\ Mumbai 400 076, India \\ e-mail: rmv@ether.chem.iitb.ernet.in
}

\begin{abstract}
This article describes the recent results obtained in our laboratory on the interaction of polyfunctional ligands with divalent alkaline earth metal ions and a few divalent transition metal ions. Treatment of $\mathrm{MCl}_{2} \cdot n \mathrm{H}_{2} \mathrm{O}(\mathrm{M}=\mathrm{Mg}, \mathrm{Ca}, \mathrm{Sr}$ or $\mathrm{Ba})$ with 2-amino benzoic acid leads to the formation of complexes $\left[\mathrm{Mg}(2-\mathrm{aba})_{2}\right](\mathbf{1})$, $\left.\left[\mathrm{Ca}(2-\mathrm{aba})_{2}\left(\mathrm{OH}_{2}\right)_{3}\right]_{\infty}(\mathbf{2}),\left[\left\{\mathrm{Sr}(2-\mathrm{aba})_{2}\left(\mathrm{OH}_{2}\right)_{2}\right\}_{2} \cdot \mathrm{H}_{2} \mathrm{O}\right)\right]_{\infty}(\mathbf{3}),\left[\mathrm{Ba}(2-\mathrm{aba})_{2}\left(\mathrm{OH}_{2}\right)\right]_{\infty}(\mathbf{4})$, respectively. While the calcium ions in $\mathbf{2}$ are hepta-coordinated, the strontium and barium ions in $\mathbf{3}$ and $\mathbf{4}$ reveal a coordination number of nine apart from additional metal-metal interactions. Apart from the carboxylate functionality, the amino group also binds to the metal centres in the case of strontium and barium complexes $\mathbf{3}$ and $\mathbf{4}$. Complexes $\left[\left\{\mathrm{Mg}\left(\mathrm{H}_{2} \mathrm{O}\right)_{6}\right\}(4-\mathrm{aba})_{2} \cdot 2 \mathrm{H}_{2} \mathrm{O}\right](5),\left[\mathrm{Ca}(4-\mathrm{aba})_{2}\left(\mathrm{H}_{2} \mathrm{O}\right)_{2}\right]$ (6) prepared from 4-aminobenzoic acid reveal more open or layered structures. Interaction of 2-mercaptobenzoic acid with $\mathrm{MCl}_{2} \cdot 6 \mathrm{H}_{2} \mathrm{O}(\mathrm{M}=\mathrm{Mg}, \mathrm{Ca})$, however, leads to the oxidation of the thiol group resulting in the disulphide 2,2'-dithiobis(benzoic acid). New metal-organic framework based hydrogen-bonded porous solids $[\{\mathrm{M}(\mathrm{btec})$ $\left.\left(\mathrm{OH}_{2}\right)_{4}\right\}_{n} \cdot n\left(\mathrm{C}_{4} \mathrm{H}_{12} \mathrm{~N}_{2}\right) \cdot 4 n \mathrm{H}_{2} \mathrm{O}$ ] (btec $=1,2,4,5$-benzene tetracarboxylate) $(\mathrm{M}=\mathrm{Co} \mathbf{9} ; \mathrm{Ni}$ 10; $\mathrm{Zn} \mathrm{11)} \mathrm{have} \mathrm{been} \mathrm{synthesized} \mathrm{from} 1,2,4,5$-benzene tetracarboxylic acid in the presence of piperazine. These compounds are made up of extensively hydrogenbonded alternating layers of anionic $\mathrm{M}$-btec co-ordination polymer and piperazinium cations. Compounds 2-11 described herein form polymeric networks in the solidstate with the aid of different coordinating capabilities of the carboxylate anions hydrogen bonding interactions.
\end{abstract}

Keywords. Coordination polymer; aminobenzoic acid; benzene tetracarboxylic acid; alkaline earth metals; supramolecular chemistry.

\section{Introduction}

Microporous inorganic materials like zeolites find widespread use in heterogeneous catalysis, adsorption and ion exchange processes. The rigidity and stability of such framework allow for shape and size selective inclusion of guest molecules. The design of supramolecular structures with interesting structural and magnetic properties has fuelled research in this relatively new area. Due to their interesting structural features as well as the anticipated properties of the extended solids, advances in these fields are growing rapidly.

The designed construction of extended, porous, co-ordination polymer frameworks from soluble molecular building blocks represents one of the most challenging issues in

*For correspondence 
synthetic chemistry ${ }^{1,2}$. Given the diversity of the ligands and metal-ligand co-ordination chemistry, there exists extensive opportunities for synthesizing co-ordination polymers with novel, porous architectures. The first challenge is to control the orientation and stereochemistry of the building blocks, in the solid state in order to achieve a target molecular topology and architecture. Therefore, the synthesis of co-ordination polymers which have structures analogous to zeolites, may yield a new generation of multidimensional network which contain channels or cavities of various sizes and shapes, unobserved as yet, in zeolites ${ }^{3}$. Polymers produced this way have been termed as modular solids since they are assembled from discrete molecules ${ }^{2}$.

In the construction of such hybrid inorganic-organic polymer network, the choice of the ligand which forms a basic building block, plays a very important role in determining the pore size $^{2}$. This is especially true as demonstrated by recent reports on new, microporous, metal-organic frameworks that have been assembled with multifunctional organic molecules and several transition metal ions using a modular approach ${ }^{4}$. All these complexes exhibit supramolecular behaviour due to the heavy association through covalent and hydrogen bonds. It has now been well documented that by a judicious choice of building units, it is possible to produce extended cationic, anionic and neutral porous networks with unusual pore architecture and functions.

The ligands as well as the metal ions may be tailored to effect highly selective inclusion of incoming guests. Aromatic acids are expected to form rigid stable coordination polymers on account of their appropriately placed functional groups which are attached to a rigid template such as a benzene ring (scheme 1). Several research groups in the last five years have synthesized polymeric networks with zeolite-like morphologies using these acids as well as other types of ligands. A more detailed description of these newly unraveled structures can be found in recent reviews in this area ${ }^{1}$. The objective of this mini-review is to mainly highlight our own research efforts in this area.

\section{Results and discussion}

Our interests in this area are in the use of multifunctional ligands whose donor atoms are located on a rigid phenyl group. For this purpose, we are particularly interested in<smiles>O=C(O)c1ccc(C(=O)O)cc1</smiles><smiles>O=C(O)c1cc(C(=O)O)cc(C(=O)O)c1</smiles><smiles>N#Cc1ccc([Si](c2ccc(C#N)cc2)(c2ccc(C#N)cc2)c2ccc(C#N)cc2)cc1</smiles><smiles>O=C(O)C1C2CC3(C(=O)O)CC(C(=O)O)(C2)CC1(C(=O)O)C3</smiles>

Scheme 1. 
<smiles>Nc1ccccc1C(=O)O</smiles>

(a)<smiles>O=C(O)c1ccccc1S</smiles><smiles>Nc1cccc(C(=O)O)c1</smiles>

(b)<smiles>Nc1ccc(C(=O)O)cc1</smiles>

(c)<smiles>O=C(O)c1cc(C(=O)O)c(C(=O)O)cc1C(=O)O</smiles>

(e)

Scheme 2.

employing aromatic amino acids such as a-c shown in scheme 2 for two reasons. They contain carboxylate and amino functionalities, which are known to behave differently towards metal centres because of differences in their hard-soft donor characteristics. Secondly, by choosing the second substituent's position (namely, ortho, meta, or para; i.e. 60,120 or $180^{\circ}$ between the functional groups) one can easily vary the resultant supramolecular organization. For similar reasons, the well-known mercaptobenzoic acid (d) was also chosen as the building block in our initial studies.

The considerable success that has been achieved in recent years in using benzene dicarboxylic/tricarboxylic acids as building blocks has prompted us to study the suitability 1,2,4,5-benzene tetracarboxylic acid (e), in conjunction with several amines for this purpose. Moreover, the relative disposition of the four carboxylate ligands on the phenyl group is likely to offer several intriguing structures which are essentially based on a one-dimensional co-ordination polymer.

\subsection{Coordination polymers derived from 2-aminobenzoic acid}

The metal complexes 1-4 are best prepared by mixing group 2 metal chloride hydrates with 2-amino benzoic acid (2-abaH) under basic conditions $(p \mathrm{H} \sim 10-12)$ from an aqueous solution (scheme 3$)^{5}$. In the case of magnesium, an insoluble precipitate is obtained instantaneously, whereas compounds $\mathbf{2 - 4}$ are fairly soluble in water and form $\mathrm{X}$-ray quality single crystals after several days from the reaction mixtures. The 2-aba complexes 1-4 have been extensively characterized by both analytical and spectroscopic methods. Additionally, the solid state structures of 2-4 have been unambiguously established by single crystal X-ray diffraction studies.

The IR spectra of these complexes reveal that all the complexes, except for magnesium complex $\mathbf{1}$, contain at least one coordinated or un-coordinated water molecule. This was further supported by subsequent thermal studies of these complexes and single X-ray crystal structure. Further, the IR spectral studies clearly establish the non-participation of the amino group in coordination to the metal in $\mathbf{2}$, whereas the amino group co-ordinates to strontium and barium ions in complexes $\mathbf{3}$ and $\mathbf{4}$, respectively. This observation could be attributed to the increase in the soft character of the metal ions on going down the group. 


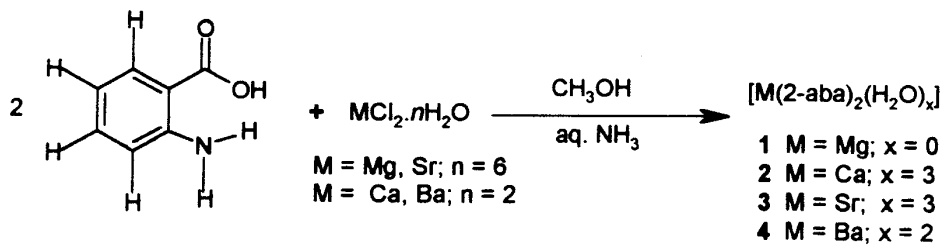

Scheme 3 .

However, it is surprising to note that a simple 1:2 M:L complex, which has no coordinated water molecules is formed in the case of magnesium complex $\mathbf{1}$. Synthesis of the compound using other bases such as $\mathrm{NaOH}$ or $\mathrm{KOH}$, in place of aqueous ammonia, did not change the composition of the final product obtained. In all cases the resultant product yielded the same analytical data. This observation clearly contrasts several known magnesium complexes wherein $\mathrm{Mg}^{2+}$ ion preferentially binds to water molecules, often in the form of $\left[\mathrm{Mg}\left(\mathrm{OH}_{2}\right)_{6}\right]^{2+}$.

Crystal structure of 2: The calcium atoms in $\left[\mathrm{Ca}(2-\mathrm{aba})_{2}\left(\mathrm{OH}_{2}\right)_{3}\right]_{\infty}$ are hepta-coordinated. Four of the coordination sites in $\mathbf{2}$ are occupied by bridging carboxylate oxygen atoms. To complete the coordination sphere, each calcium atom is further complexed to three water molecules. The net result is the formation of an eight-membered ring $\left(\mathrm{Ca}_{2} \mathrm{C}_{2} \mathrm{O}_{4}\right)$ between every adjacent calcium atom which ultimately leads to the formation of a onedimensional polymeric chain of calcium atoms (see figure 1). The amino group of the anthranilate ligand does not directly take part in the coordination to the metal, but forms a hydrogen bond with the oxygen atoms of a coordinated water molecule from a neighbouring polymeric chain. In addition, $\mathrm{O}-\mathrm{H} . . . \mathrm{O}$ hydrogen bonds exist in-between the polymeric chains which originate from either the coordinated water molecules or the carboxylate oxygen atoms. Thus, the one-dimensional polymeric chains are connected with each other resulting in the formation of a supramolecular metal-organic framework as is seen in figure 2. The distance of 4.699(1) $\AA$ between the neighbouring calcium atoms along the chain is much longer than the observed value of $4.05 \AA$ between the calcium atoms in the case of the related complex [Ca(4-aminosalicylate) (acetate) $\left(\mathrm{H}_{2} \mathrm{O}\right) \mathrm{H}_{2} \mathrm{O}^{6}$. The coordination geometry around the calcium atom is irregular and can, at best, be described as a heavily distorted pentagonal bipyramidal, with the angles around calcium varying from 73.7 to $163.9^{\circ}$.

Crystal structure of 3: In spite of identical elemental composition, the solid-state structures of calcium complex 2 and $\left.\left[\left\{\mathrm{Sr}(2-\mathrm{aba})_{2}(\mathrm{OH})_{2}\right)_{2}\right\} \cdot \mathrm{H}_{2} \mathrm{O}\right]_{\infty}(3)$ completely differ from each other. For example, the strontium atoms in $\mathbf{3}$ are nine-coordinated with a weak metal-metal interaction. The two types of anthranilate ligands in $\mathbf{3}$ show an entirely different coordinating behaviour (figure 3). Like in $\mathbf{2}$, strontium atoms in $\mathbf{3}$ also form a zigzag polymeric chain with the help of these two contrastingly different anthranilate ligands. The most important observation to note here is the ability of the amino group of one of the anthranilate ligands to take part in coordination with neighbouring strontium atom. Moreover, the hydrogen-bonding interaction in $\mathbf{3}$ becomes more complex due to the presence of an additional lattice water molecule apart from the three coordinated water molecules. There are as many as nine different $\mathrm{O}-\mathrm{H} \ldots \mathrm{O}, \mathrm{N}-\mathrm{H} \ldots \mathrm{O} . \mathrm{C}-\mathrm{H} \ldots \mathrm{O}$ 
hydrogen bonds which are responsible for the supramolecular assembly depicted in figure

4. In general, the coordination geometry, $\mathrm{Sr}-\mathrm{O}$ distances, and $\mathrm{O}-\mathrm{Sr}-\mathrm{O}$ angles in $\mathbf{3}$ are

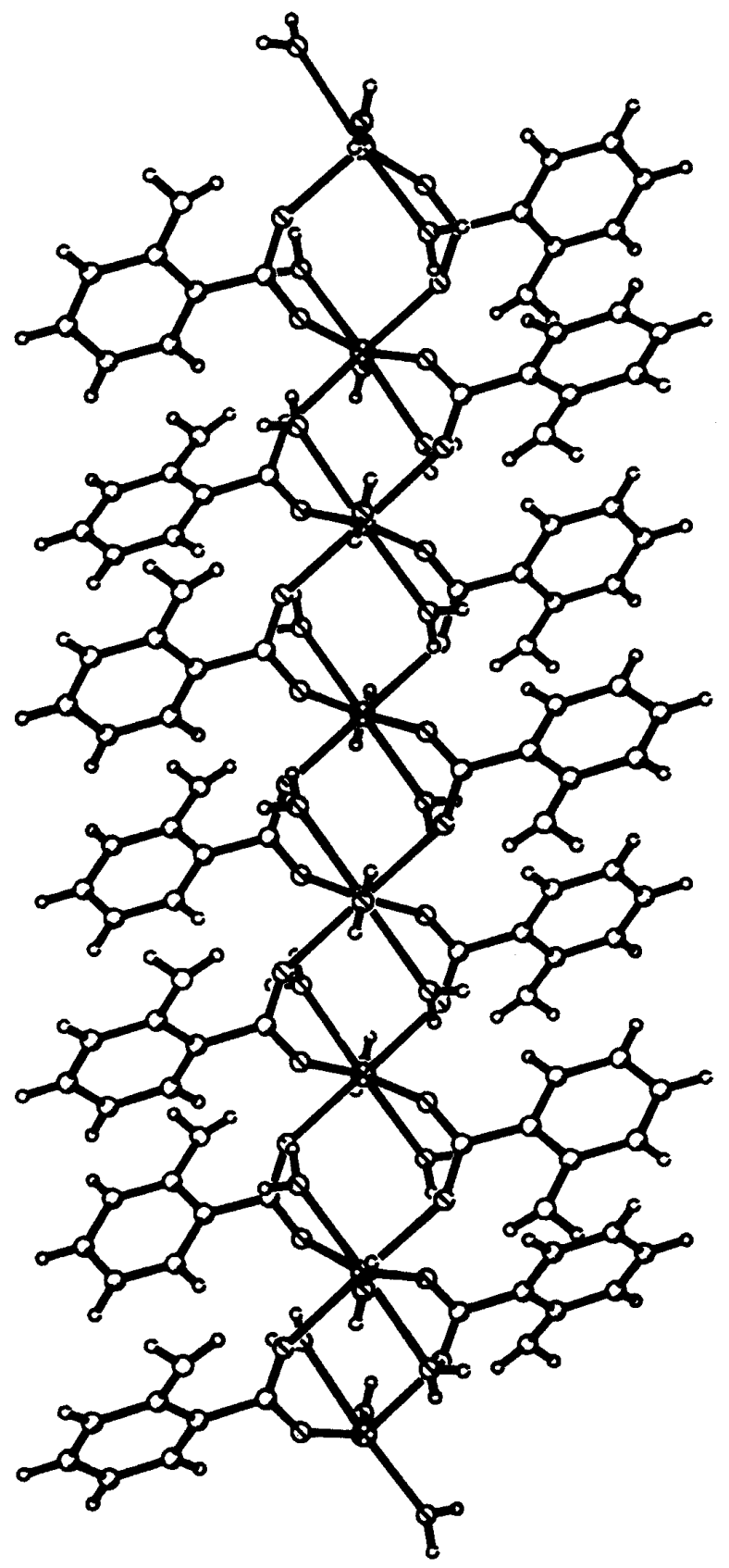

Figure 1. Illustration of the polymeric chain formed by $\left[\mathrm{Ca}(2-\mathrm{aba})_{2}\left(\mathrm{OH}_{2}\right)_{3}\right]_{\infty}(2)$ in solid-state. 


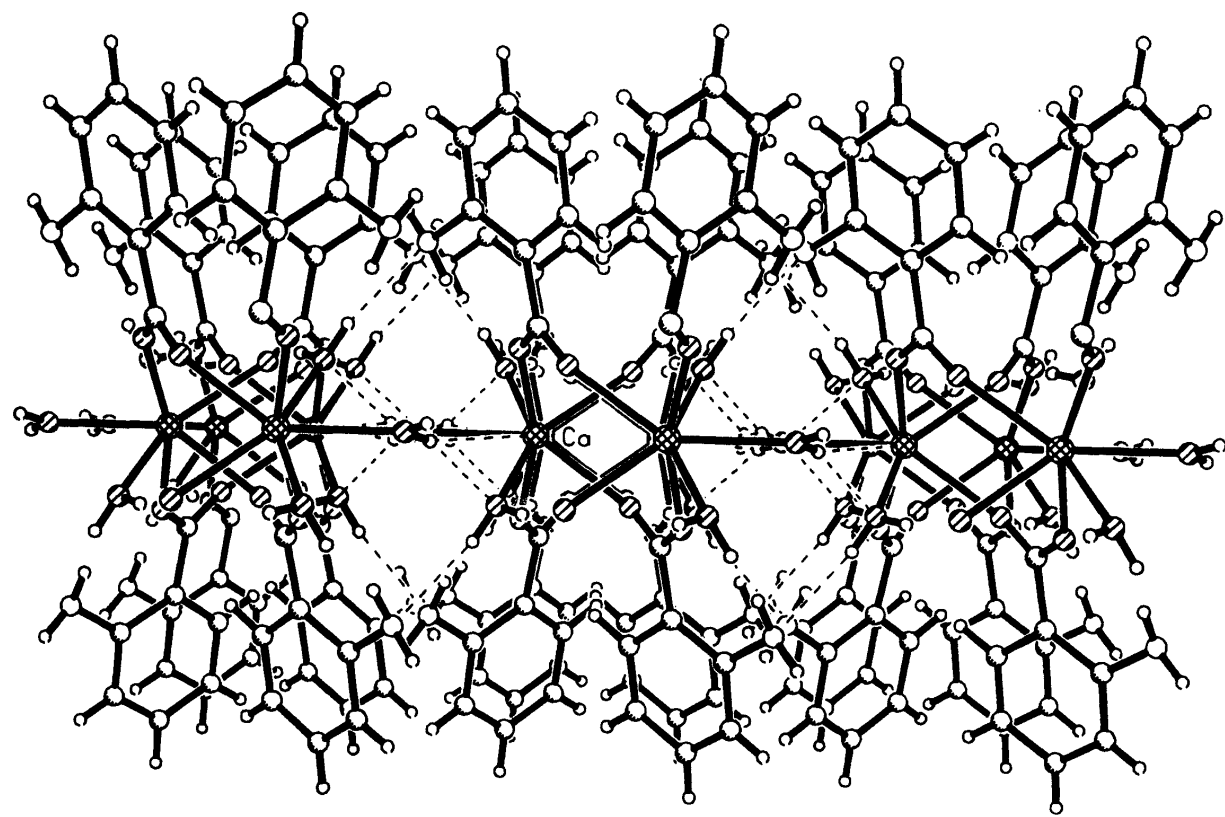

Figure 2. Packing diagram showing hydrogen bonding interactions between polymeric chains in $\left[\mathrm{Ca}(2-\mathrm{aba})_{2}\left(\mathrm{OH}_{2}\right)_{3}\right]_{\infty}(\mathbf{2})$.

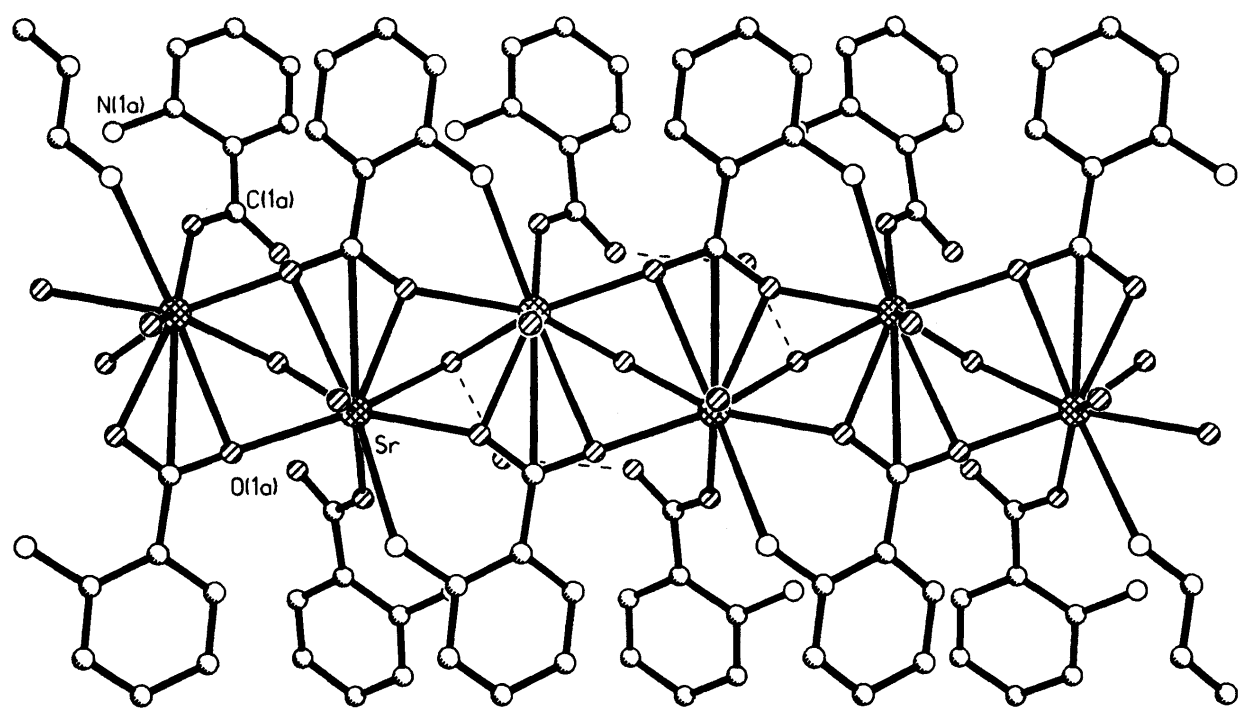

Figure 3. Illustration of the polymeric chain formed by $\left[\left\{\mathrm{Sr}(2-\mathrm{aba})_{2}\left(\mathrm{OH}_{2}\right)_{2}\right\} \cdot \mathrm{H}_{2} \mathrm{O}\right]_{\infty}$ (3) in solid-state. 


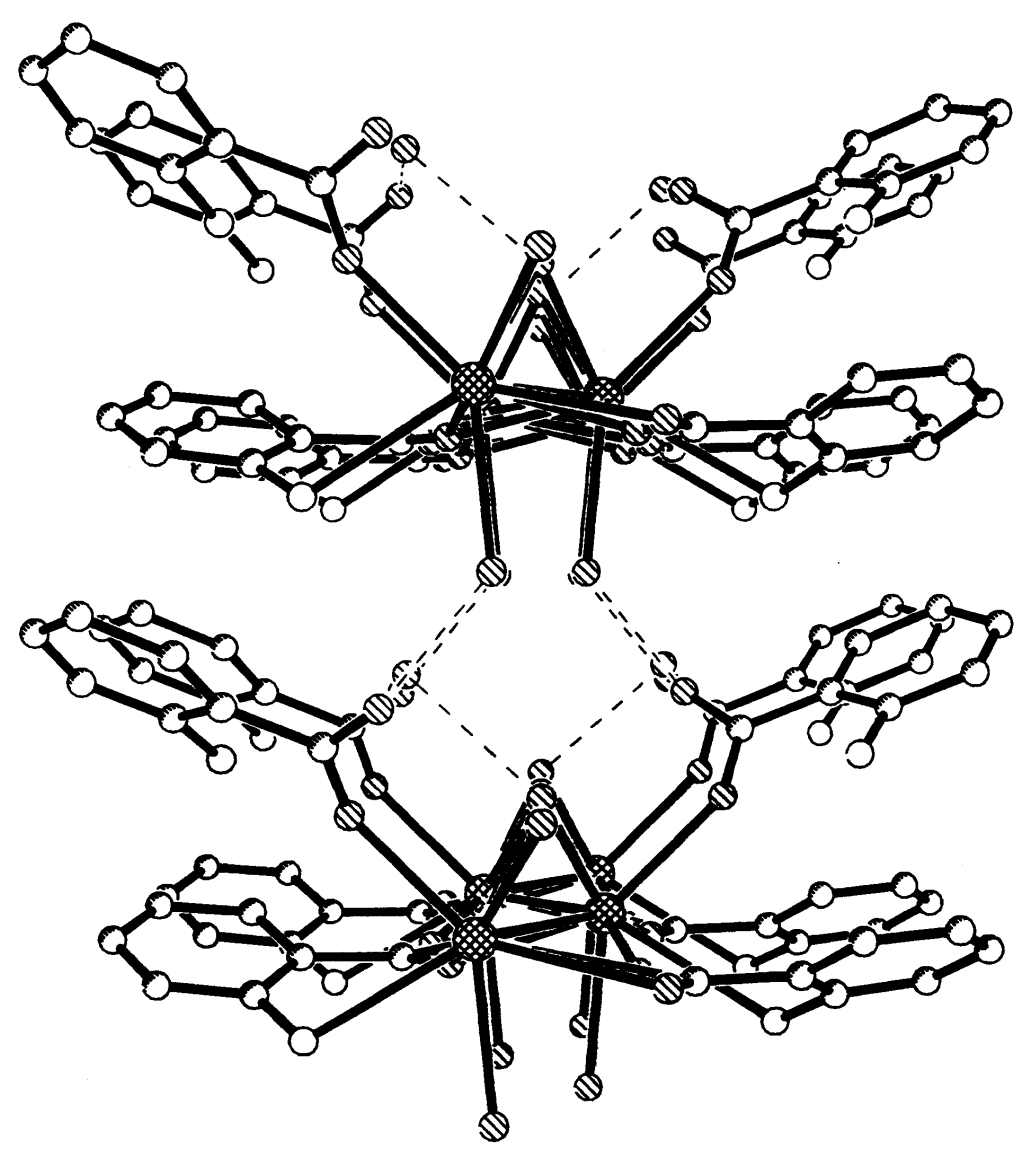

Figure 4. Packing diagram showing hydrogen bonding interactions between polymeric chains in $\left[\left\{\mathrm{Sr}(2-\mathrm{aba})_{2}\left(\mathrm{OH}_{2}\right)_{2}\right\} \cdot \mathrm{H}_{2} \mathrm{O}\right]_{\infty}(\mathbf{3})$.

comparable to those found in [Sr(L-glutamate) $\cdot 6 \mathrm{H}_{2} \mathrm{O}$ ] complex reported by Schmidbaur et $a l^{7}$ and other Sr-carboxylate complexes ${ }^{8,9}$, although no amino coordination was found in the glutamate complex. Another important structural feature in $\mathbf{3}$ is the rather unusually short $\mathrm{Sr}$...Sr distance of $3.92 \AA$.

Crystal structure of 4: The barium atoms in $\mathbf{4}$ are nine-coordinated as in $\mathbf{3}$, although the coordination environment around the barium atom varies significantly. Each barium atom is coordinated by six carboxylate oxygen atoms, two bridging water molecules and one amino group. Two chelate rings are found around each barium atom; the first is a fourmembered chelate ring formed by the carboxylate group of one of the anthranilate ligands, while the second is a six-membered chelate ring that is formed by the carboxyl atom and the amino nitrogen. Apart from chelating, the two anthranilate ligands are also engaged in bridging the neighbouring barium atoms. The net result is the formation of a two-dimensional polymer, which is schematically represented in figure 5. The water molecule bridges the two adjacent barium atoms along the polymeric chain. Due to the presence of the coordinated water molecule and the coordinated and free amino groups, a few hydrogen bonds are found in the solid state. 


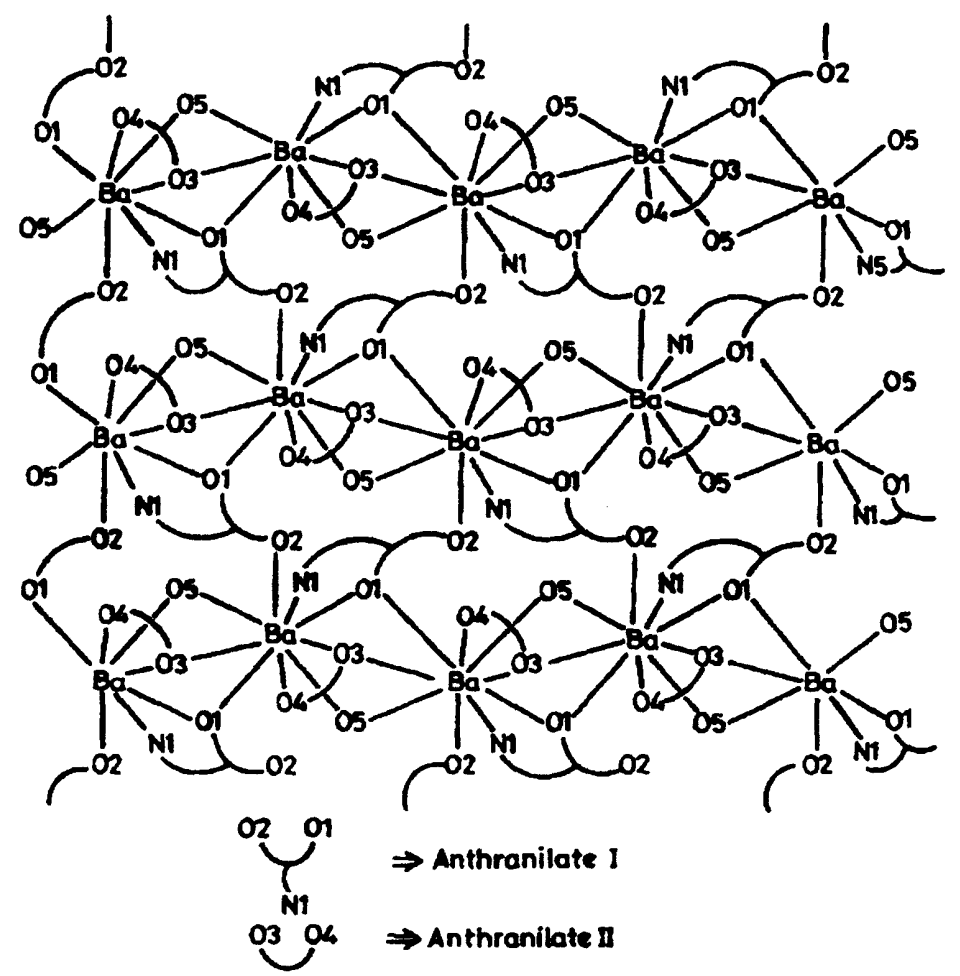

Figure 5. Schematic diagram of the coordination network in $\left[\mathrm{Ba}(2-\mathrm{aba})_{2}\left(\mathrm{OH}_{2}\right)\right]_{\infty}(4)$.

Thus, a rich coordination chemistry of the 2-aminobenzoic acid with group 2 metal ions, which are normally reluctant to form coordination compounds, has been unraveled. The observed modes of coordination of the 2-amino benzoate ligand, are illustrated in figure 6 .

\subsection{Coordination polymers derived from 4-aminobenzoic acid ${ }^{10}$}

While the relative ortho positioning of the $-\mathrm{NH}_{2}$ and $\mathrm{COO}^{-}$groups in 2-aba led to the isolation of solids 1-4, it was expected that the use of 4-amino benzoic acid (4-abaH) would lead to novel layered-type structures due to the presence of potentially hydrogen bond forming $-\mathrm{NH}_{2}$ group in the para position. In order to verify this supposition, the synthesis of compounds $\mathbf{5}$ and $\mathbf{6}$ were accomplished by the reaction of $\mathrm{MCl}_{2} \cdot 6 \mathrm{H}_{2} \mathrm{O}$ $(\mathrm{M}=\mathrm{Mg}$ or $\mathrm{Ca})$ with 4 -abaH ${ }^{10}$. The analytically pure products were characterized by their IR, ${ }^{1} \mathrm{H}$ NMR and UV-vis spectral data. The aqueous solutions of both $\mathbf{5}$ and $\mathbf{6}$ were found to be almost neutral $(p \mathrm{H}=7.1$ for 5 and 6.5 for 6 at $0.06 \mathrm{M})$. The IR spectra show several strong absorptions in the region $3200-3500 \mathrm{~cm}^{-1}$ indicating the presence of water molecules with varying degrees of hydrogen bonding. Further, in case of $\mathbf{1}$, a fairly large change in the observed $\mathrm{n}(\mathrm{C}=\mathrm{O})$ value $\left(\sim 50 \mathrm{~cm}^{-1}\right)$ is suggestive of the presence of uncoordinated aminobenzoates which are involved in only a secondary interaction to the $\mathrm{Mg}^{2+}$ ion (as in the recently reported 1-methylcytosine complexes of $\mathrm{Mg}$ and $\mathrm{Cd}$ ) ${ }^{11}$. 
<smiles>Nc1ccccc1C(O)O[Si]</smiles><smiles>[Si][O+]1OC2[Si]Nc3ccccc3C1[Si]2</smiles><smiles></smiles><smiles>[M]OC(O[M])c1ccccc1N</smiles>

Figure 6. Schematic depiction of the coordination behaviour of the 2-aba ligands in complexes 2, 3 and 4 .

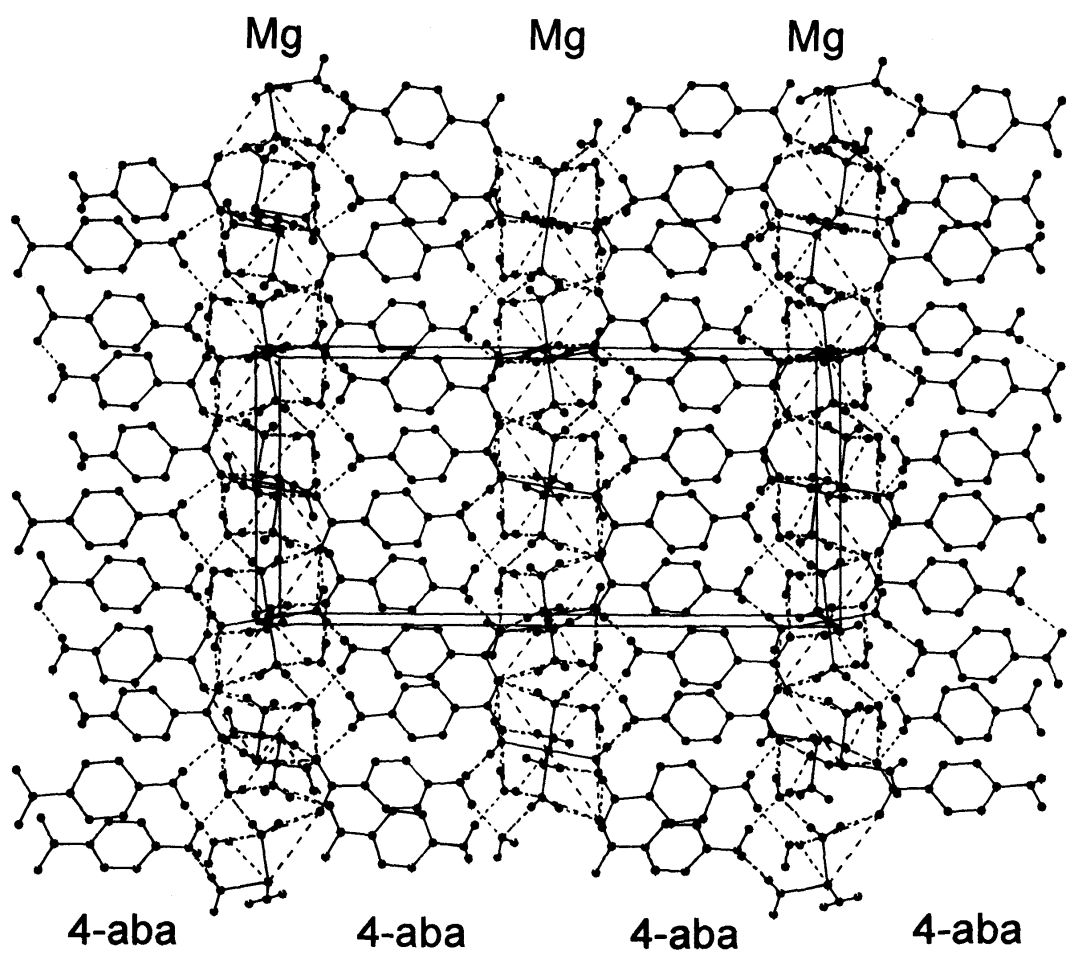

Figure 7. Packing diagram of $\left[\mathrm{Mg}\left(\mathrm{H}_{2} \mathrm{O}\right)_{6}\right]\left[(4-\mathrm{aba})_{2}\right] \cdot 2 \mathrm{H}_{2} \mathrm{O}$ (5) in the solid state showing alternating organic and inorganic layers. 
Crystal structure of 5: The structure of $\left[\mathrm{Mg}\left(\mathrm{H}_{2} \mathrm{O}\right)_{6}\right]\left[(4-\mathrm{aba})_{2}\right] \cdot 2 \mathrm{H}_{2} \mathrm{O} 5$ comprises of an hexa-aqua $\mathrm{Mg}^{2+}$ ion which has only secondary interactions with two 4-aminobenzoate anions through the coordinated $\mathrm{H}_{2} \mathrm{O}$ molecules. The $\mathrm{Mg}^{2+}$ ion forms a nearly ideal octahedral hexa-aqua complex. The three different $\mathrm{Mg}-\mathrm{OH}_{2}$ distances observed in the molecules (2.070)(3), 2.071(3), and 2.096(3) $\AA$ ) is comparable to the corresponding distances observed for $\left[\mathrm{Mg}(\text { salicylate })_{2}\left(\mathrm{OH}_{2}\right)_{4}\right],\left[\mathrm{Mg}(2 \text {-aminosalicylate })_{2}\left(\mathrm{OH}_{2}\right)_{4}\right]$, and [ $\mathrm{Mg}(2,6$-pyridinedicarboxylate $\left.)\left(\mathrm{OH}_{2}\right)_{3}\right]\left(\mathrm{OH}_{2}\right)$. The view down $b$ axis, as shown in figure 7 , illustrates the supramolecular assembly of alternating columns of cationic $\left[\mathrm{Mg}\left(\mathrm{H}_{2} \mathrm{O}\right)_{6}\right]^{2+}$ and anionic 4-aminobenzoate ligands. The extensive hydrogen bonding between the Mg-bound water molecules, 4-aminobenzoate anions and the lattice water molecules hold the cationic and the anionic part of the molecule together. In the small pores produced by the formation of these alternating layers of cationic and anionic columns, lattice water molecules are trapped inside.

Crystal structure of 6: The basic structural motif in $\left[\mathrm{Ca}(4-\mathrm{aba})_{2}\left(\mathrm{H}_{2} \mathrm{O}\right)_{2}\right](6)$ is made up of a coordination polymer of eight-coordinated calcium ions as against the heptacoordinated calcium ions found in the 2-aminobenzoate complex $\left[\mathrm{Ca}(2-\mathrm{aba})_{2}\left(\mathrm{OH}_{2}\right)_{3}\right]_{\infty}$. Each $\mathrm{Ca}^{2+}$ ion is bound to two 4-aminobenzoate anions and two water molecules. One of the aminobenzoate ligands, apart from acting as a chelating ligand through its carboxylate group, also bridges the neighbouring $\mathrm{Ca}^{2+}$ ions on either side of the polymeric chain (figure 8). As a net result, the $\mathrm{Ca}^{2+}$ ions form infinite zigzag chains. A view down the axis

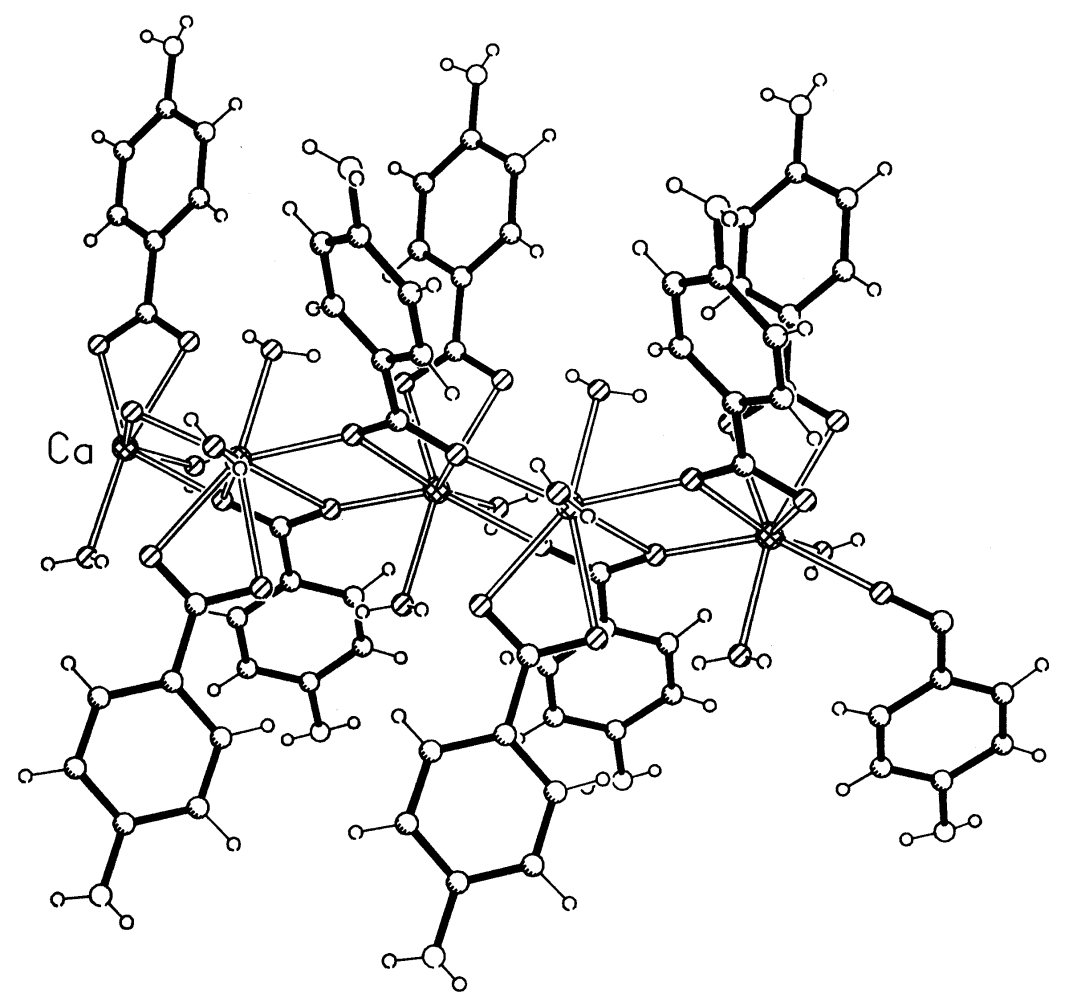

Figure 8. Illustration of the polymeric chain formed by $\left[\mathrm{Ca}(4-\mathrm{aba})_{2}\left(\mathrm{OH}_{2}\right)_{2}\right]_{\infty}(\mathbf{6})$ in solid-state. 


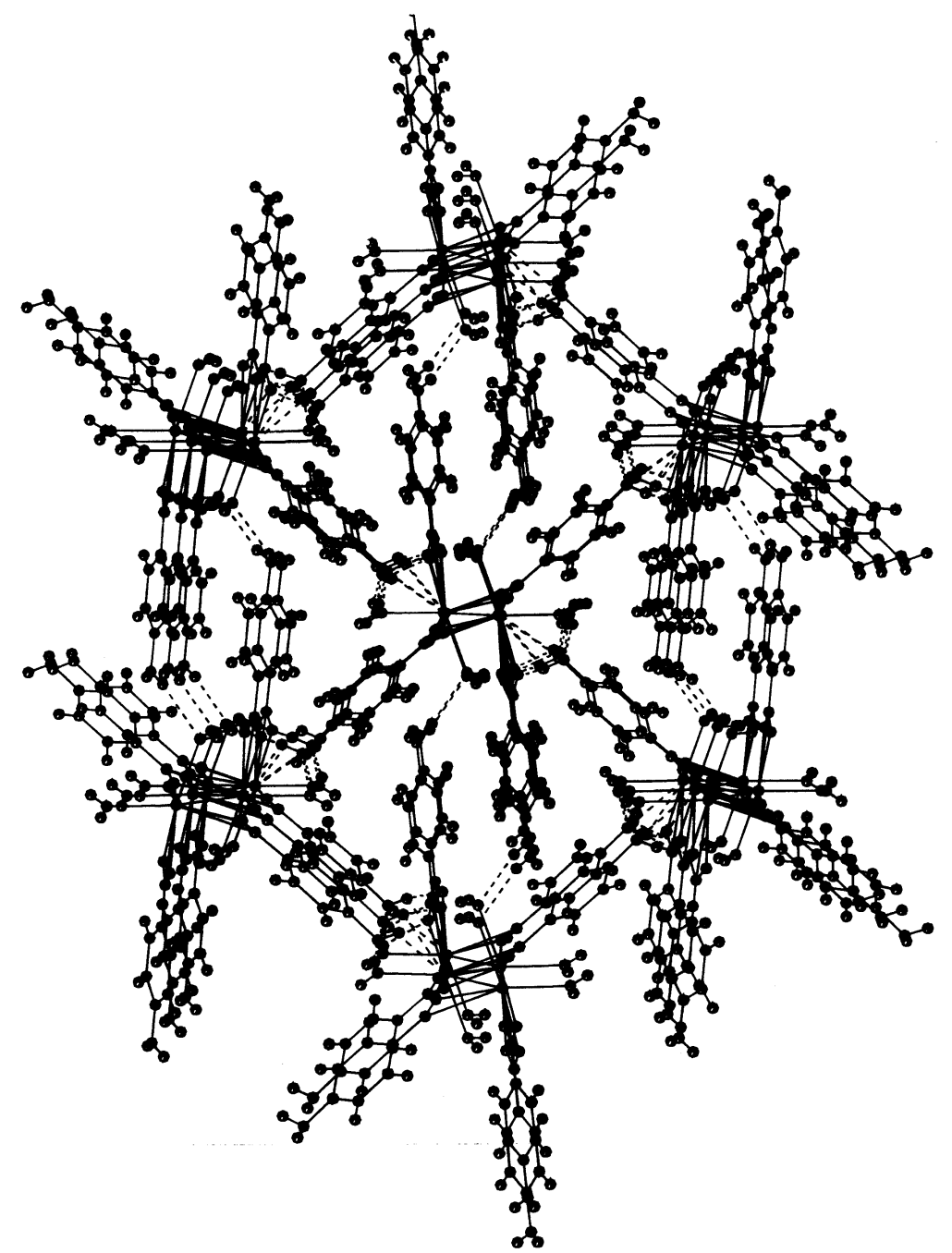

Figure 9. Packing diagram showing hydrogen bonding interactions between polymeric chains in $\left[\mathrm{Ca}(4-\mathrm{aba})_{2}\left(\mathrm{OH}_{2}\right)_{2}\right]_{\infty}(\mathbf{6})$.

of the polymer propagation reveals that each of these chains is surrounded by six similar chains which are held together by hydrogen bonds (figure 9). Further, the cooperative hydrogen bonding between the $-\mathrm{NH}_{2}$ group of the organic ligand and the coordinated $\mathrm{H}_{2} \mathrm{O}$ molecule of the adjacent $\mathrm{Ca}^{2+}$ ions manifests into the formation of small $\mathrm{p}-\mathrm{p}$ stacks of the aryl rings throughout the lattice.

It should be noted that, apart from the change in the coordination number, there are principal differences between 2 and the corresponding 2-aminobenzoate complex [Ca(2aba $\left.)_{2}\left(\mathrm{OH}_{2}\right)_{3}\right]_{\infty}$. For example, while the 2 -aminobenzoate ligands in $\left[\mathrm{Ca}(2 \text {-aba })_{2}\left(\mathrm{OH}_{2}\right)_{3}\right]_{\infty}$ exclusively function as bridging ligands between the adjacent calcium ions, both the 4aminobenzoate ligands in $\mathbf{2}$ chelate to the metal apart from one these ligands also bridging the adjacent calcium atoms. 


\subsection{Polymeric structures derived from 2-mercaptobenzoic acid ${ }^{12}$}

In order to evaluate the utility of the thiol group (in place of the amino group as above) in forming coordination compounds with group 2 metal cations 2-mercaptobenzoic acid was reacted with $\mathrm{MCl}_{2} \cdot 6 \mathrm{H}_{2} \mathrm{O}(\mathrm{M}=\mathrm{Mg}$ or $\mathrm{Ca})$. The outcome of these reactions was the oxidative coupling of the $-\mathrm{SH}$ group of thiosalicylic acid, resulting in the formation of 2,2'-dithiobis(benzoic acid) (scheme 4). Oxidation of thiols into disulphides is a wellknown reaction. There are reports in literature describing the formation of disulphides in the presence of air or on a TLC plate in the presence of iodine. It is generally believed that the formation of disulphides from $\mathrm{S}-\mathrm{H}$ groups is more facile than the conversion of $\mathrm{Se}-\mathrm{H}$ or Te-H groups into the corresponding diselenides or ditellurides ${ }^{13}$.

While in the reaction with $\mathrm{CaCl}_{2}$, the oxidized product 2,2'-dithiobis(benzoic acid) further reacts with $\mathrm{CaCl}_{2} \cdot 6 \mathrm{H}_{2} \mathrm{O}$ to yield 8 , quite surprisingly in the reaction with $\mathrm{MgCl}_{2}$, the isolated $\mathbf{7}$ product did not contain any magnesium. The crystals of disulphide adduct 7 and the calcium complex $\mathbf{8}$ are almost insoluble in all solvents including water, and hence were characterized only in the solid state. The product 7 was identified, based on its elemental analysis, IR spectrum, and a single crystal X-ray diffraction study, as an adduct which consists of organo-disulphide 2,2'-dithiobis(benzoic acid) and its monoammonium salt in a 1:1 ratio. Similarly, the elemental analysis, IR spectrum and a single $\mathrm{X}$-ray crystal structure established the Ca-complex to be $\mathrm{Ca}-\left(\mathrm{OOC}-\mathrm{C}_{6} \mathrm{H}_{4}-\mathrm{S}-\mathrm{S}-\mathrm{C}_{6} \mathrm{H}_{4}-\right.$ $\left.\mathrm{COO})\left(\mathrm{H}_{2} \mathrm{O}\right)_{2}\right] n$.

Crystal structure of 7: The asymmetric part of the unit cell in 7 contains one molecule of 2,2'-dithiobis(benzoic acid) and one molecule of its ammonium salt (scheme 4). All the $\mathrm{S}-\mathrm{S}$ bond lengths in the asymmetric part are almost equal and compare well with the literature values of other disulphides ${ }^{14}$. The $\mathrm{C}-\mathrm{S}-\mathrm{S}-\mathrm{C}$ dihedral angles in molecules 1 and 2 are $-84.6(2)^{\circ}$ and $-101.01(2)^{\circ}$, respectively. These values indicate that the aryl substituents on the two sulphur atoms are neither cis (expected value $0^{\circ}$ ) nor trans

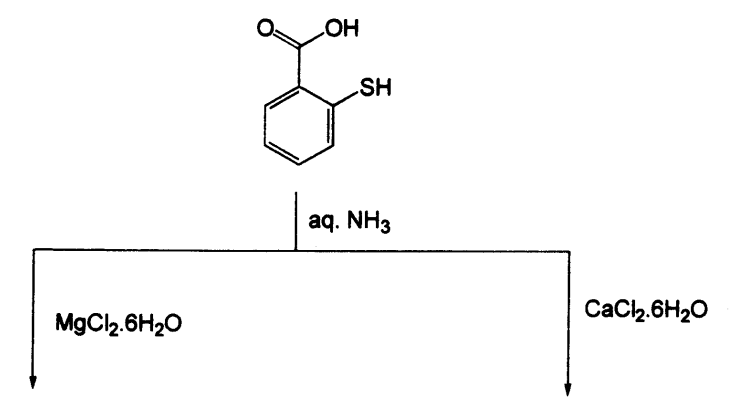<smiles>O=C(O)c1ccccc1SSc1ccccc1C(=O)O</smiles>

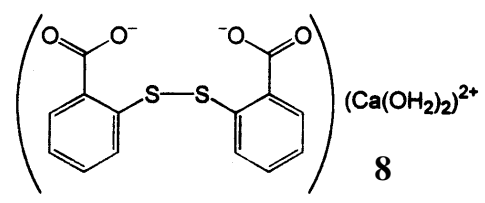

Scheme 4. 


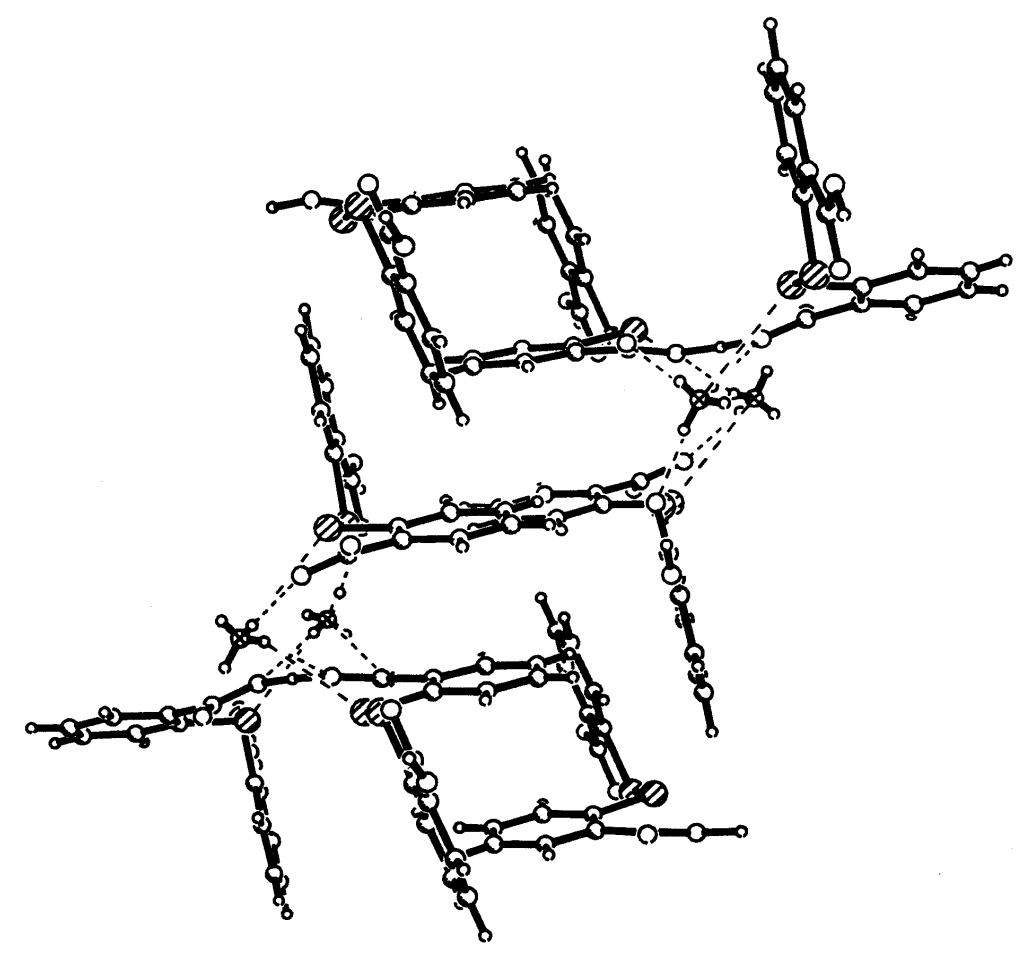

Figure 10. Packing of 2,2'-dithiobis-benzoic acid and mono-ammonium salt (adduct 7) in the solid-state.

(expected value $180^{\circ}$ ) with respect to each other. The observed values rather indicate an approximate perpendicular disposition of the aryl rings with respect to each other (see figure 10). The formation of these five-membered rings through the non-bonded contacts probably influences the observed $\mathrm{C}-\mathrm{S}-\mathrm{S}-\mathrm{C}$ dihedral angles and hence the conformation of the molecule. The presence of the $\mathrm{NH}_{4}{ }^{+}$ion is the source of extensive hydrogen bonds in the lattice. Apart from the $\mathrm{O}-\mathrm{H}$...O hydrogen bonding between the adjacent neighbours, additional $\mathrm{N}-\mathrm{H}$... O and $\mathrm{N}-\mathrm{H}$...S hydrogen bonds are formed to eventually result in a supramolecular array of disulphide adducts.

Crystal structure of 8 : The calcium complex of 2,2'-dithiobis(benzoic acid) $\mathrm{Ca}$ (OOC$\left.\left.\mathrm{C}_{6} \mathrm{H}_{4}-\mathrm{S}-\mathrm{S}-\mathrm{C}_{6} \mathrm{H}_{4}-\mathrm{COO}\right)\left(\mathrm{H}_{2} \mathrm{O}\right)_{2}\right]_{n}$ forms a perfect coordination polymer (figure 11). The two carboxylate anions of the 2,2'-dithiobis(benzoate) ligand act as a bridge between polymeric chains of calcium ions. Each of these carboxylate anions is involved both in chelating and bridging modes of coordination within the same calcium chain. Thus, a three-dimensional polymeric structure as shown in figure $11 \mathrm{~b}$ is formed in the solid state with the formation of channels inside the lattice. The difference map is suggestive of the presence of some disordered ethanol molecules being trapped in these channels. Further characterization of this product by thermal analysis will clearly reveal the exact nature of the occluded species. 


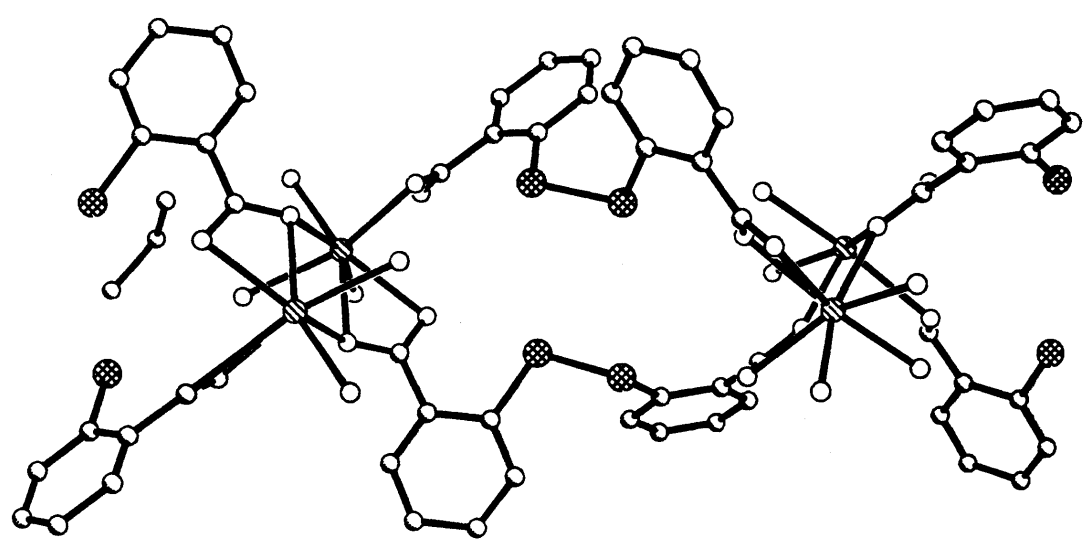

b

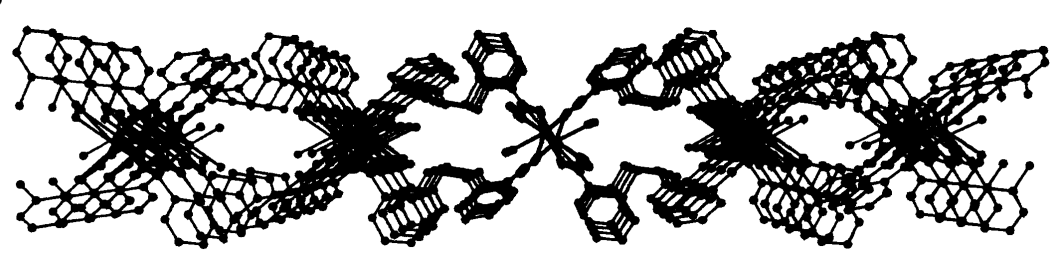

Figure 11. (a) A fragment of the polymeric chain formed by $\left[\mathrm{Ca}\left(\mathrm{OOC}-\mathrm{C}_{6} \mathrm{H}_{4}-\mathrm{S}-\mathrm{S}-\right.\right.$ $\left.\left.\mathrm{C}_{6} \mathrm{H}_{4}-\mathrm{COO}\right)\left(\mathrm{H}_{2} \mathrm{O}\right)_{2}\right]_{n}(\mathbf{8})$ in the solid-state; (b) its packing diagram.

$$
\begin{aligned}
& \underset{\substack{\mathrm{M}=\mathrm{Co}, \mathrm{Ni} \\
\mathrm{ZnSO}_{4} \cdot 7 \mathrm{H}_{2} \mathrm{O}}}{\mathrm{MCl}_{2} \cdot 6 \mathrm{H}_{2} \mathrm{O}}+\mathrm{H}_{4}^{\text {btec })} \\
& \longrightarrow \begin{array}{c}
\mathrm{H}_{2} \mathrm{O} \\
\longrightarrow
\end{array}
\end{aligned}
$$

Scheme 5.

\subsection{Coordination polymers of 1,2,4,5-benzene tetracarboxylic acid ${ }^{15}$}

As earlier described the use of divalent transition metal ions and benzene di- and tricarboxylic acids (scheme 1) as modular precursors in designing a number of new metal-organic polymeric solids prompted us to investigate the supramolecular structure forming capabilities of the 1,2,4,5-benzene tetracarboxylic acid $\left(\mathrm{H}_{4} \mathrm{BTEC}\right)$. Although it may be argued that, due to a stearic reasons, it is unlikely that all four carboxyl groups of $\mathrm{H}_{4} \mathrm{BTEC}$ would take part in co-ordination to the metal, even the presence of free $-\mathrm{COOH}$ groups would lead to formation of new and novel types of porous solids aided by weak 
hydrogen bonding. Keeping this in mind, we have studied the extended solid forming ability of $\mathrm{H}_{4} \mathrm{BTEC}$ towards divalent transition metal ions such as $\mathrm{Co}^{2+}, \mathrm{Ni}^{2+}$, and $\mathrm{Zn}^{2+}$ in the presence of an added donor amine.

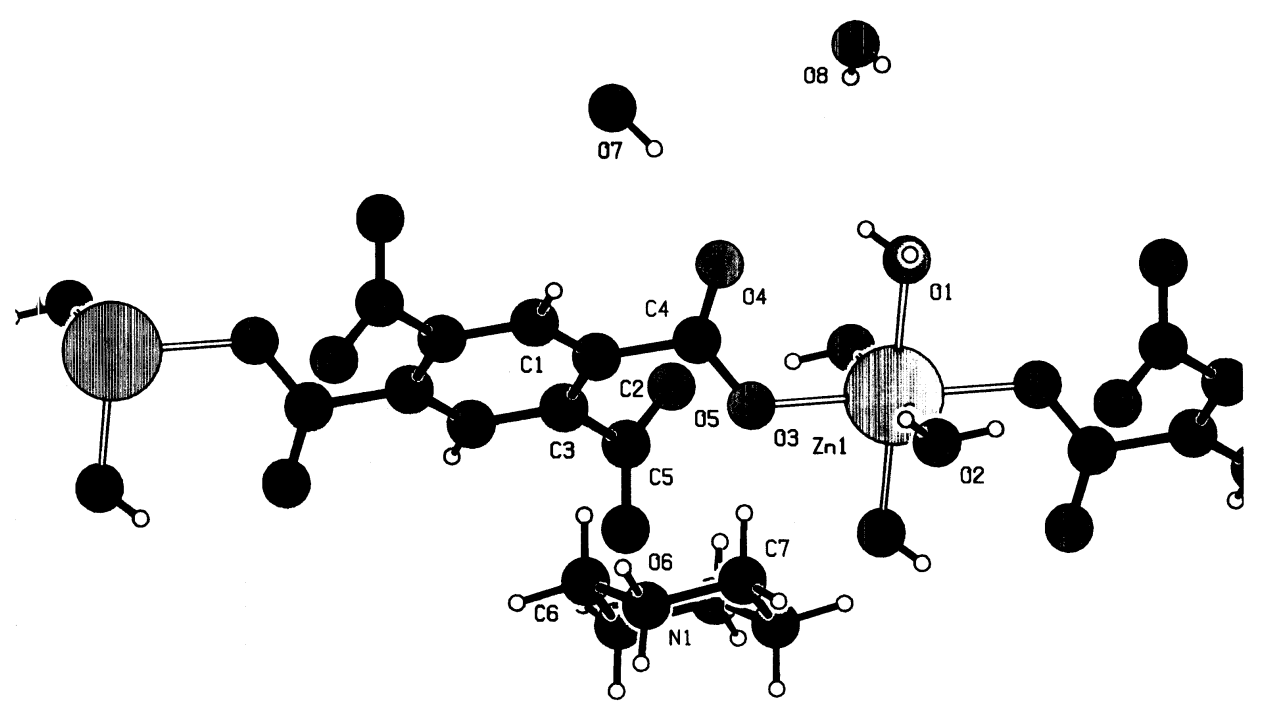

Figure 12. Illustration of the repeating unit in the coordination polymer $\left.\left[\mathrm{Zn}(\mathrm{btec})\left(\mathrm{OH}_{2}\right)_{4}\right]_{n} \cdot n\left(\mathrm{C}_{4} \mathrm{H}_{12} \mathrm{~N}_{2}\right) \cdot 4 n \mathrm{H}_{2} \mathrm{O}\right](\mathbf{1 1})$.

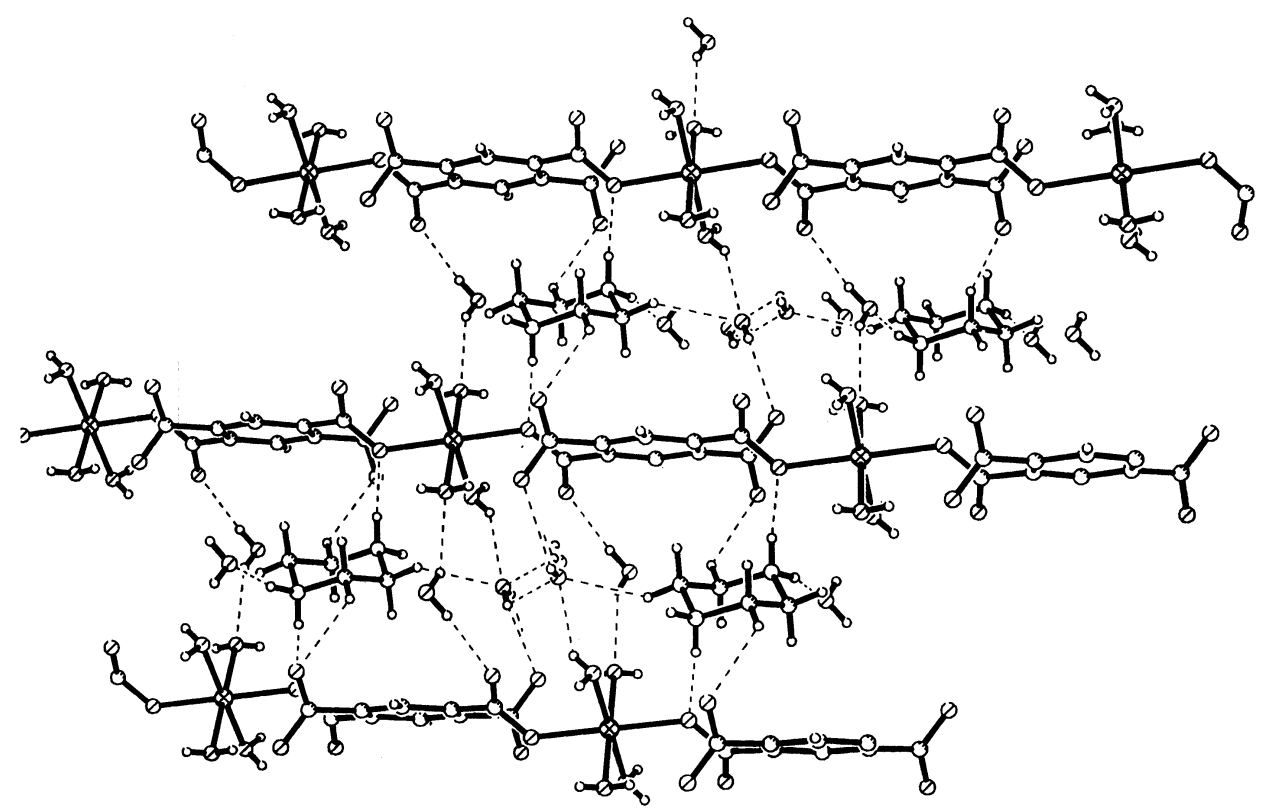

Figure 13. Diagram depicting the metal-organic polymer and the organic amine layers alternation in $\left[\mathrm{Ni}(\mathrm{btec})\left(\mathrm{OH}_{2}\right)_{4}\right]_{n} \cdot n\left(\mathrm{C}_{4} \mathrm{H}_{12} \mathrm{~N}_{2}\right) \cdot 4 n \mathrm{H}_{2} \mathrm{O}(\mathbf{1 0})$. 
The compounds $\left.\left[\mathrm{M}(\mathrm{BTEC})(\mathrm{OH})_{2}\right)_{4}\right]_{n} \cdot n\left(\mathrm{C}_{4} \mathrm{H}_{12} \mathrm{~N}_{2}\right) \cdot 4 n \mathrm{H}_{2} \mathrm{O}(\mathrm{M}=\mathrm{Co}, \mathbf{9}, \mathrm{Ni}, \mathbf{1 0}, \mathrm{Zn}, \mathbf{1 1})$ are obtained in good yields by a slow diffusion controlled reaction between an aqueous solution of a suitable transition metal salt and $\mathrm{H}_{4} \mathrm{BTEC}$, in the presence of piperazine hexahydrate (scheme 5) ${ }^{15}$. The single crystals (pink, Co; green Ni; colourless $\mathrm{Zn}$ ), whose size is dependent on the rate of crystallization and the concentration of the initial solution, are like most organic solvents, completely insoluble in water and once again forcing us to employ only solid-state techniques to characterize the products (elemental analysis, IR and DR UV-vis spectral studies, thermal analysis and single crystal X-ray diffraction studies). The difference between the asymmetric $\left(1618 \mathrm{~cm}^{-1}\right)$ and symmetric $\left(1361 \mathrm{~cm}^{-1}\right)$ stretching frequencies in the IR spectrum is consistent with the unidentate terminal mode of co-ordination of the carboxylate groups. The diffuse reflectance UVvisible spectrum of the compounds are consistent with the expected values for the octahedral complexes of these metal ions ${ }^{16}$.

All the three compounds are isomorphous and crystallize in the triclinic centrosymmetric space group. The molecular structure depicting the repeating unit in the

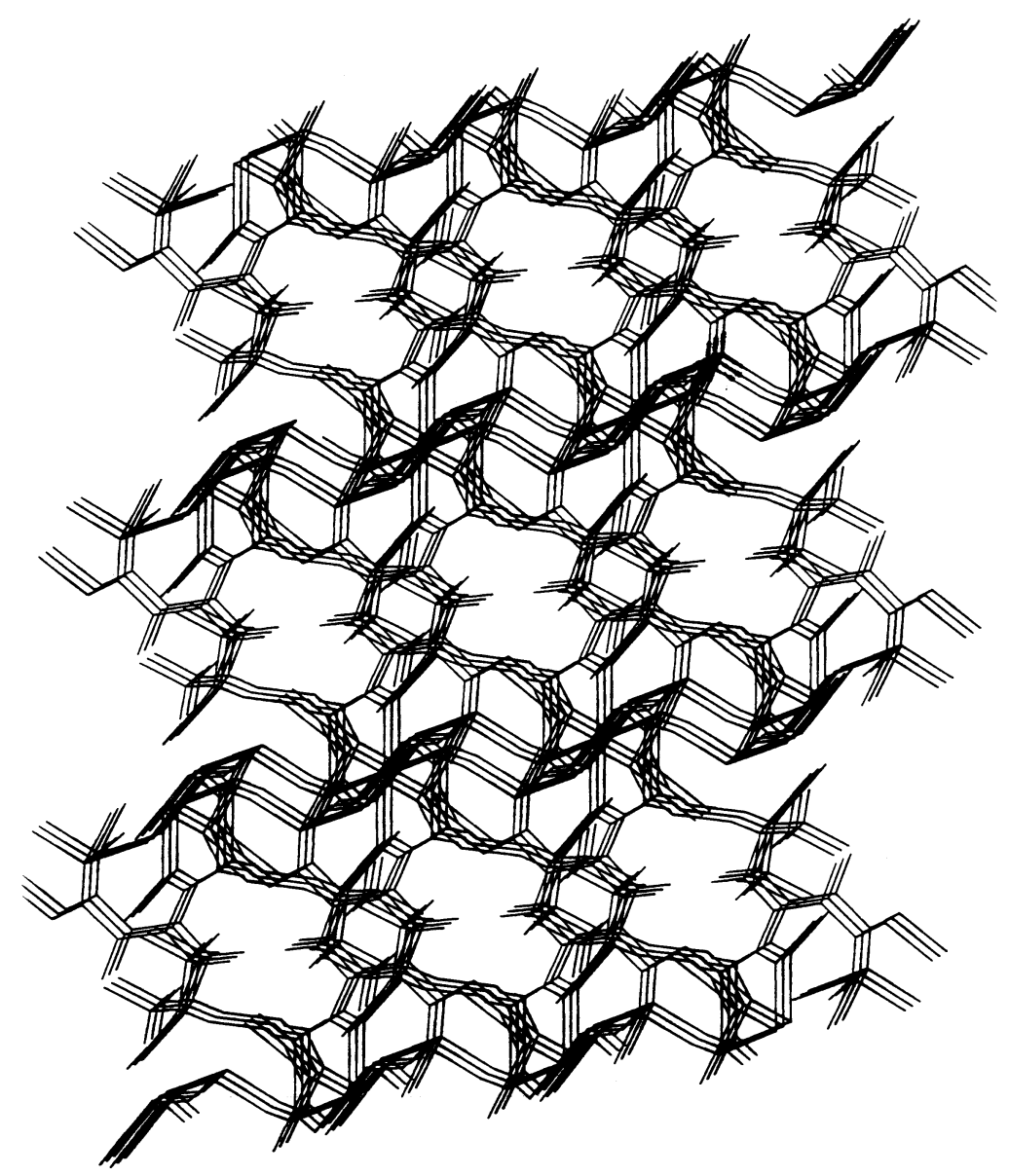

Figure 14. Three-dimensional packing of $\left[\mathrm{Co}(\mathrm{btec})\left(\mathrm{OH}_{2}\right)_{4}\right]_{n} \cdot n\left(\mathrm{C}_{4} \mathrm{H}_{12} \mathrm{~N}_{2}\right) \cdot 4 n \mathrm{H}_{2} \mathrm{O}(\mathbf{9})$ in the solid-state resulting in the formation of micro-channels. Lattice water molecules omitted for clarity. 


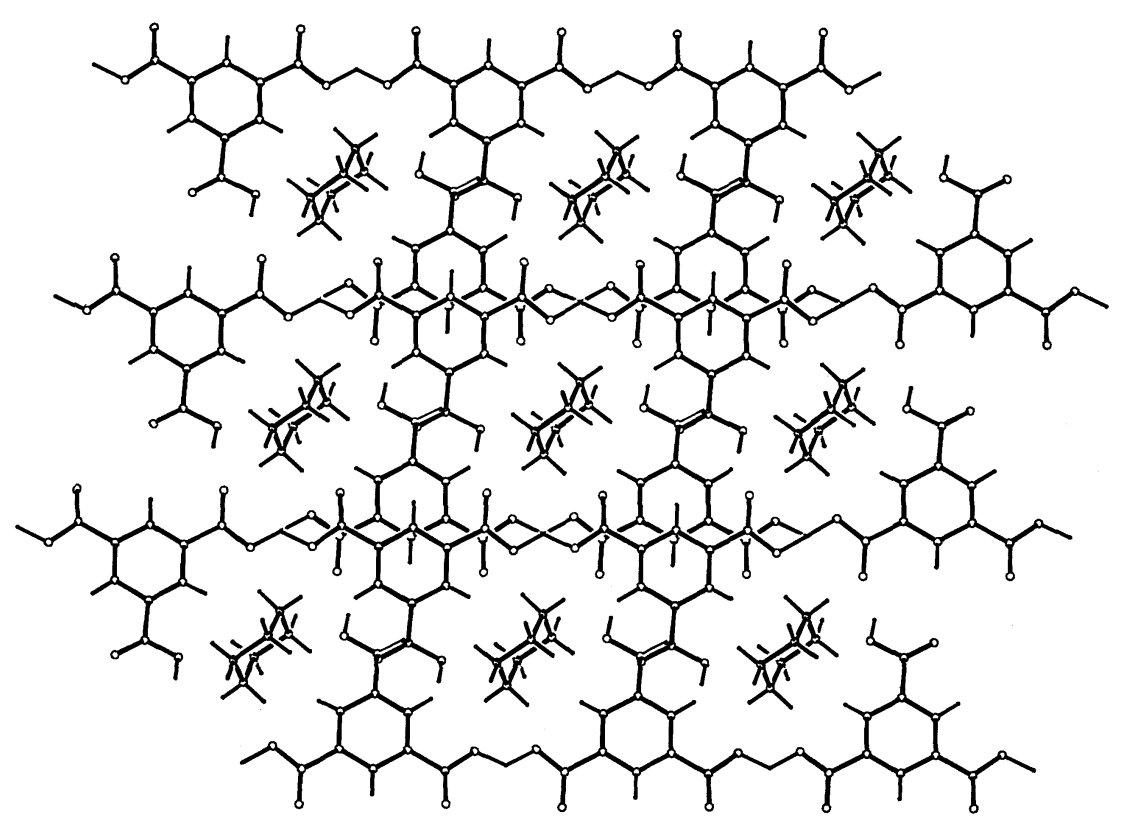

Figure 15. Supramolecular architecture in $2\left[\mathrm{C}_{6} \mathrm{H}_{3}(\mathrm{COOH})_{2}(\mathrm{COO})\right]\left[\right.$ piperazine $\left.\cdot \mathrm{H}_{2} \mathrm{O}\right]$ (12).

lattice of the zinc derivative is seen in figure 12. The central metal ion is octahedrally coordinated. While four water molecules surround each metal ion in the form of a square plane, the axial positions are ligated by carboxylate anions coming from two different BTEC ligands (in other words, the BTEC ligands bridge adjacent metal ions through the 1,4-carboxylate ligands in a unidentate fashion), leading to the formation of a one-dimensional polymeric structure. These coordination polymeric chains stack one over the other with water molecules with the piperezinium cations sandwiched between them yielding a layered structure (figure 13). The packing diagram of this layered structure shows the presence of micropores of the dimensions $\sim 4 \AA$ within the crystal lattice (figure 14).

Thermal studies on the cobalt and nickel derivatives show a stepwise weight loss behaviour of the water molecules. The first weight loss occurring at $50-90^{\circ} \mathrm{C}$ corresponds to the loss of two uncoordinated water molecules, while a further weight loss observed at $100-170^{\circ} \mathrm{C}$ could be attributed to the loss of two more un-coordinated and two coordinated water molecules. In fact, heating pink coloured cobalt coordination polymer 9 at this temperature range results in the change of colour to blue, indicating the change of coordination geometry to tetrahedral. Diffuse reflectance visible spectrum of this heattreated sample further testifies to the formation of a tetrahedral structure around cobalt ions. Exposing this dehydrated sample to moist air results in the tetrahedral complex reverting back to the original octahedral structure. A similar colour change was observed for the nickel case (green to greenish-yellow, and back).

Recently, our attempts to generate coordination polymers of BTC in the presence of piperazine resulted in the isolation of an all-organic polymeric compound $2\left[\mathrm{C}_{6} \mathrm{H}_{3}(\mathrm{COOH})_{2}(\mathrm{COO})\right]\left[\right.$ piperazine $\left.\cdot \mathrm{H}_{2}\right](\mathbf{1 2})$ with no metal ions, as the side product ${ }^{17}$. Figure 15 depicts the supramolecular architecture derived from $\mathrm{H}_{3} \mathrm{BTC}$ and piperazine. 
We are presently exploring the possibilities of extending this approach to incorporate other types of amines inside the channels formed by 1,3,5-benzenetetracarboxylic acid.

\section{Conclusion}

Generation of novel supramolecular structures based on coordination polymeric networks continues to be a fertile area of research and a number of new framework structures are being regularly reported in modern literature. By choosing amino carboxylic acids as organic templates, we have shown that a number of new structures with large structural variations can be realized by just changing the size and nature of the central metal ion. It has also been shown that the change of the position of the amino group (from ortho to para) results in large variations in the final structures. Similarly, our preliminary results on the use of $\mathrm{H}_{4} \mathrm{BTEC}$ as an organic module is suggestive of the potential of this largely unexplored ligand in the synthesis of new coordination polymers. Our present efforts in this area centre around the incorporation of amines and other types of small guest molecules within the coordination polymeric structures formed by $\mathrm{H}_{3} \mathrm{BTC}$ and $\mathrm{H}_{4} \mathrm{BTEC}$.

\section{Acknowledgements}

This work was supported by a research grant from the Council of Scientific and Industrial Research and Department of Science and Technology, New Delhi. RM acknowledges the Department of Atomic Energy, Mumbai, for a research award in Chemistry. We thank the DST-funded X-ray facility at IIT-Bombay, and Mr H G Schmidt, University of Göttingen for the single crystal X-ray diffraction data.

\section{References}

1. Hagrman P J, Hagrman D and Zubeita J 1999 Angew. Chem., Int. Ed. Engl. 382638

2. Yaghi O M, Davis C E, Li H and Groy T L 1998 Acc. Chem. Res. 31474

3. Yaghi O M, Davis C E, Li G and Li H 1997 J. Am. Chem. Soc. 1192861

4. (a) Atwood J L, Groeneman R H and MacGillivray L R 1999 Inorg. Chem. 38208 (b) Yaghi O M, Li H and Groy T L 1996 J. Am. Chem. Soc. 1189096 (c) Choi H J and Suh M P 1998 J. Am. Chem. Soc. 12010622

5. Murugavel R, Karambelkar V V, Anantharaman G and Walawalkar M G 2000 Inorg. Chem. 391381

6. Cole L B and Holt E M 1989 Inorg. Chim. Acta 160195

7. Schmidbaur H, Bach I, Wilkinson D L and Müller G 1989 Chem. Ber. 1221433

8. Poonia N S and Bajaj A V 1979 Chem. Rev. 79389

9. (a) Briaggman B and Oskarsom A 1977 Acta Crystallogr. B33 1900 (b) Palmer K J, Wong R Y and Lewis J C 1972 Acta Crystallogr. Sect B28 223

10. Murugavel R, Karambelkar V V, Anantharaman G and Walawalkar M G 2000 Indian J. Chem. Section A (in press)

11. Westerhausen H 1991 Inorg. Chem. 3090

12. Murugavel R, Anantharaman G and Walawalkar M G 1998 (unpublished results)

13. Block E, Eswarakrishnan V, Gernon M, Ofori-okai G, Saha C, Tang K and Zubieta J 1989 J. Am. Chem. Soc. 111658

14. Hogg D R 1979 In Organic compounds of sulphur, selenium and tellurium (Cambridge: University Press) 5153

15. Murugavel R, Krishnamurthy D and Sathiyendiran M 1999 (manuscript in preparation)

16. Lever A B P 1984 In Inorganic electronic spectroscopy (Amsterdam: Elsevier Science) p 480

17. Murugavel R and Krishnamurthy D 1999 (unpublished results) 